\title{
Ocena skłonności do pękania gorącego w warunkach wymuszonych odkształceń złączy spawanych stopu Inconel 617
}

\author{
The assessment of susceptibility to hot cracking \\ under forced deformation conditions \\ in welded joints of Inconel 617 alloy
}

\section{Streszczenie}

Rozwój przemysłu energetycznego uwarunkowany jest wieloma czynnikami, do których przede wszystkim należy polityka Unii Europejskiej zobowiązująca przemysł do obniżenia emisji zanieczyszczeń $\mathrm{NO}_{x}, \mathrm{CO}_{2}, \mathrm{SO}_{2}$ do atmosfery. Podwyższenie parametrów pary jest możliwe dzięki zastosowaniu zaawansowanych materiałów, do których należą stopy niklu. Pomimo ich wysokich właściwości mechanicznych w wysokiej temperaturze, stopy niklu należą do materiałów trudnospawalnych ze względu na pojawiające się pęknięcia gorące w spoinie oraz strefie wpływu ciepła. W artykule przedstawiono wyniki badań skłonności stopu niklu Inconel 617, który jest przeznaczony na krytyczne elementy kotła energetycznego. Badania obejmują próby technologicznego spawania w warunkach wymuszonego odkształcenia w obecności gazu obojętnego elektrodą wolframową. W próbie wyznaczono wielkość odkształcenia oraz próg kruchości wysokotemperaturowej. Uzupełnieniem badań była analiza mikrostruktury płyt próbnych z obszaru pęknięcia za pomocą mikroskopu świetlnego oraz elektronowego mikroskopu skaningowego.

Słowa kluczowe: Inconel 617; stopy niklu; próba Transvarestraint; pękanie gorące; złącza spawane

\begin{abstract}
The development of power industry depends on variety factors, which primarily include European Union policy that obliges the industry to reduce emission of $\mathrm{NO}_{\mathrm{x}}, \mathrm{CO}_{2}, \mathrm{SO}_{2}$ to the atmosphere. The increase of steam parameters is possible due to the use of advanced materials, which include nickel alloys. Despite their good mechanical properties at high temperatures, nickel alloys are difficult to weld due to the occurrence of hot cracks in the weld and the heat affected zone (HAZ). The article presents the results of susceptibility to hot cracking of Inconel 617 alloy, which is intended for critical elements of power boiler. The investigations include technological welding tests during forced deformations in the presence of inert gas with a tungsten electrode. In Transvarestraint test the amount of determination and the high temperature brittleness threshold were determined. Additionally, microanalysis tests sheets from cracking area by light microscope (LM) and scanning electron microscope (SEM) were done.
\end{abstract}

Keywords: Inconel 617 alloy; nickel alloys; Transvarestraint test; hot cracking; welded joints

\section{Wstęp}

Rozwój przemysłu energetycznego uwarunkowany jest wieloma czynnikami, do których przede wszystkim należy polityka Unii Europejskiej, która zobowiązuje przemysł do obniżenia emisji zanieczyszczeń $\mathrm{NO}_{x}, \mathrm{CO}_{2}, \mathrm{SO}_{2}$. Wraz ze wzrostem parametrów termodynamicznych pary, tj. ciśnienia i temperatury zwiększa się sprawność netto bloków energetycznych, a tym samym zmniejsza emisja zanieczyszczeń $[1 \div 3]$. Wyższe parametry, nadkrytyczne i supernadkrytyczne, są możliwe do osiągnięcia dzięki zastosowaniu zaawansowanych materiałów, do których należą stopy niklu. Jednym z nich jest stop Inconel 617, który może być wykorzystany na krytyczne elementy kotła pracujące nawet do $720^{\circ} \mathrm{C}[4,5]$. Inconel 617 jest stopem z rodziny Ni-Cr-Mo-Co o wysokich właściwościach wytrzymałościowych, dobrej odporności korozyjnej oraz odporności na utlenianie wysokotemperaturowe [6]. Pomimo jego żarowytrzymałości, stop należy do materiałów trudnospawalnych ze względu na pojawiające się pęknięcia gorące, co dyskwalifikuje złącze do użytkowania. Pęknięcia gorące mogą występować w materiale spoiny (pękanie krystalizacyjne) oraz w strefie wpływu ciepła (pękanie likwacyjne). Dotychczasowe rozważania dotyczące pękania gorącego materiałów głównie skupiały się na obecności

Mgr inż. Natalia Konieczna; dr hab. inż. Janusz Adamiec, prof. PŚl - Politechnika Śląska.

Autor korespondencyjny/Corresponding author. natalia.konieczna@polsı.pl 
zanieczyszczeń w materiale, do których należy siarka lub fosfor. Tworzyły one niskotopliwe eutektyki, a w efekcie poprzez odkształcenia dochodziło do pękania gorącego [7,8].

Rozwój metalurgii skutecznie ograniczył obecność zanieczyszczeń, jednakże zjawisko pękania gorącego jest nadal aktualne, szczególnie dla stopów niklu. Prochorow w swoich rozważaniach [9] stwierdził, że pękanie gorące zachodzi w zakresie kruchości wysokotemperaturowej podczas krystalizacji spoiny. Zakres kruchości wysokotemperaturowej obejmuje charakterystyczne temperatury, do których zalicza się temperatura utraty wytrzymałości podczas nagrzewania (NST), w której wytrzymałość materiału zmierza do zera, temperaturę utraty plastyczności podczas nagrzewania (NDT), w której plastyczność materiału zmierza do zera oraz temperatura odzyskania plastyczności podczas chłodzenia (DRT), w której pojawia się zdolność materiału do odkształcenia plastycznego [7]. Udowodniono, że im większa jest różnica między temperaturą utraty wytrzymałości podczas nagrzewania a odzyskaniem plastyczności podczas chłodzenia, tym większa jest skłonność do pękania gorącego stopu $[10,11]$.

Celem badań była ocena skłonności do pękania gorącego stopu Inconel 617 podczas technologicznej próby Transvarestraint w warunkach wymuszonych odkształceń złącza spawanego.

\section{Materiał i metodyka badań}

Materiałem do badań był stop Inconel 617 umacniany roztworowo w postaci blachy o grubości 3 i $5 \mathrm{~mm}$. Skład chemiczny stopu Inconel 617 w stanie dostawy został zweryfikowany na zgodność z normą ASME SB-168:2013 metodą fluorescencji promieniowania rentgenowskiego (XRF) za pomocą urządzenia Niton XL2. Wyniki wykonanej analizy XRF wraz z normą ASME dla blachy o grubości $3 \mathrm{~mm}$ zestawiono $w$ tablicy I. Natomiast widmo promieniowa XRF dla blachy ze stopu Inconel 617 o grubości $3 \mathrm{~mm}$ zostało przedstawione na rysunku 1. Na podstawie uzyskanych wyników stwierdzono, że badany materiał spełnia wymagania specyfikacji normy ASME SB-168:2013.

Wykonane badania obejmowały technologiczną próbę Transvarestraint symulującą spawanie w warunkach wymuszonych odkształceń. Próba ta polega na zginaniu płyt próbnych na cylindrycznym bloku matrycowym. Proces zginania odbywa się prostopadle do kierunku przetapiania metodą TIG stosując gaz osłonowy argon (rys. 2). Próby prowadzono na płytach o wymiarach $120 \times 90 \times 3 \mathrm{~mm}$ oraz o grubości $5 \mathrm{~mm}$. Proces przetapiania dla płyt o grubości $3 \mathrm{~mm}$ prowadzono natężeniem prądu wynoszącym $85 \mathrm{~A}$, a dla $5 \mathrm{~mm}$ zastosowano prąd 140 A. Prędkość spawania wynosiła 1,2 mm/s. Parametry procesu dobrano tak, aby uzyskać pełny przetop.

W próbie Transvarestraint wyznaczono wielkość odkształcenia rozumianą jako stosunek grubości płyty próbnej do podwojonego promienia krzywizny bloku matrycowego.

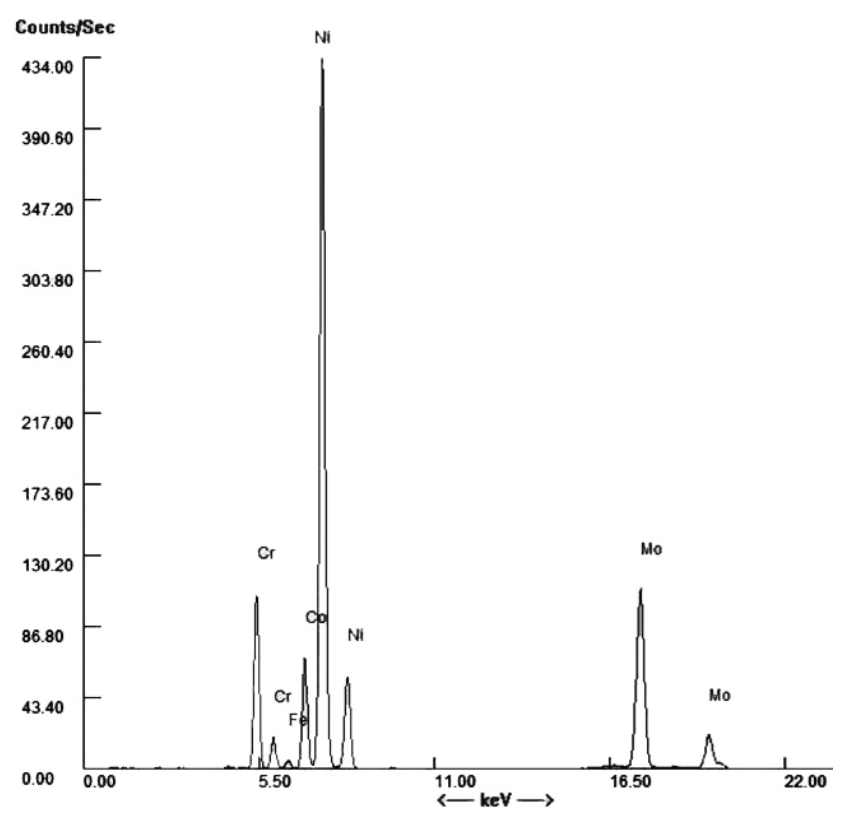

Rys. 1. Przykładowe widmo promieniowania XRF dla stopu Inconel 617

Fig. 1. The exemplary XRF spectrum for Inconel 617 alloy

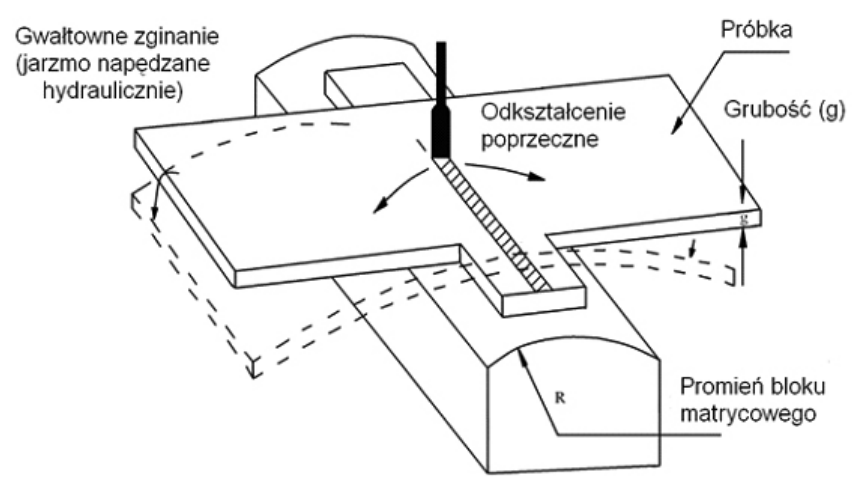

Rys. 2. Schemat próby Transvarestraint [13]

Fig. 2. The scheme of Transvarestraint test[13]

Wielkość odkształcenia podawana jest procentowo. Określono także zależność między wielkością odkształcenia a liczbą ujawnionych pęknięć, długością najdłuższego pęknięcia oraz sumą długości pęknięć. W próbie określono również próg kruchości wysokotemperaturowej. Uzupełnieniem badań była analiza metalograficzna obszaru pęknięcia prowadzona za pomocą mikroskopu stereoskopowego OLYMPUS SZX 9 (SM), mikroskopu świetlnego Olympus GX-71 (LM) oraz skaningowego mikroskopu elektronowego JEOL JCM6000 Neoscope II (SEM). Przykładowe lica przetopień z ujawnionymi pęknięciami gorącymi przedstawiono na rysunku 3. Wyznaczone zależności z wykonanej próby Transvarestraint

Tablica I. Skład chemiczny stopu niklu Inconel 617 , \% wag. [12]

Table I. Chemical composition of Inconel 617 alloy, \% wt. [12]

\begin{tabular}{|c|c|c|c|c|c|c|c|c|c|c|c|c|}
\hline \multicolumn{13}{|c|}{ Skład chemiczny stopu Inconel 617 wg ASME SB-168:2013 } \\
\hline $\mathbf{N i}$ & $\mathrm{Cr}$ & Co & Mo & Al & $\mathrm{Fe}$ & Mn & Si & $\mathrm{Ti}$ & $\mathrm{Cu}$ & S & B & C \\
\hline $\begin{array}{l}\min . \\
44,5\end{array}$ & $\begin{array}{c}20,0 \\
\div 24,0\end{array}$ & $\begin{array}{c}10,0 \\
\div 15,0\end{array}$ & $\begin{array}{c}8,0 \\
\div 10,0\end{array}$ & $\begin{array}{c}0,80 \\
\div 1,50\end{array}$ & $\max .3,0$ & $\max .1,0$ & $\max .1,0$ & $\max .0,6$ & $\max .0,5$ & $\begin{array}{l}\max . \\
0,015\end{array}$ & $\begin{array}{l}\max . \\
0,006\end{array}$ & $\begin{array}{c}0,05 \\
\div 0,15\end{array}$ \\
\hline \multicolumn{13}{|c|}{ Skład chemiczny stopu Inconel 617 wg XRF } \\
\hline $\mathrm{Ni}$ & $\mathrm{Cr}$ & Co & Mo & Al & $\mathrm{Fe}$ & Mn & Si & $\mathrm{Ti}$ & $\mathrm{Cu}$ & S & B & C \\
\hline 55,14 & 21,80 & 11,52 & 8,69 & - & 0,71 & - & - & 0,44 & - & - & - & - \\
\hline
\end{tabular}



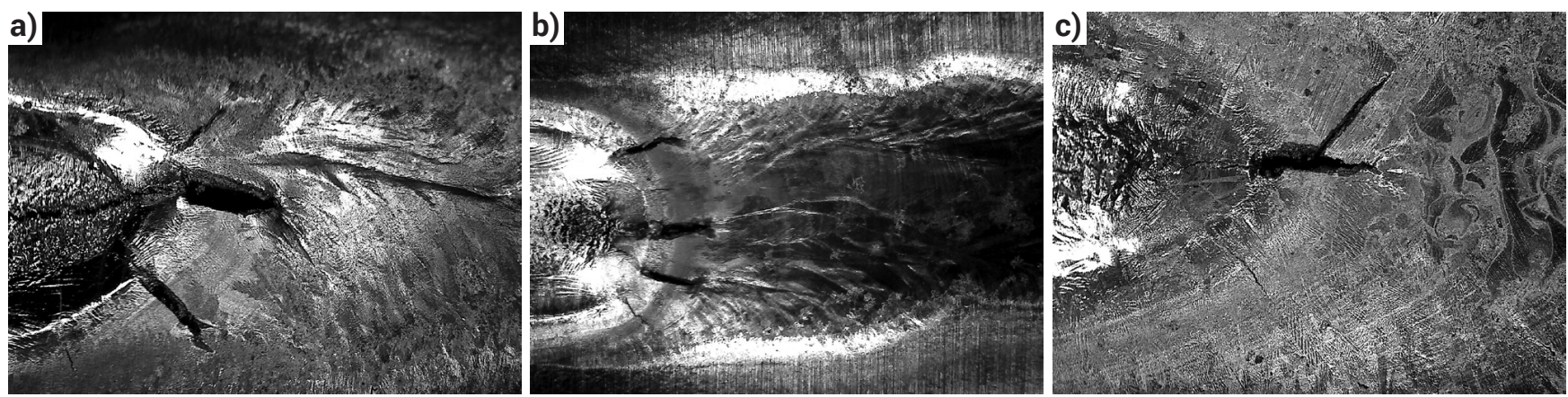

Rys. 3. Lica przetopień blachy ze stopu Inconel 617 o grubości $3 \mathrm{~mm}$ z widocznymi pęknięciami: a) promień gięcia $38 \mathrm{~mm}$, najdłuższe pęknięcie $3,0 \mathrm{~mm}$, b) promień gięcia $85 \mathrm{~mm}$, najdłuższe pęknięcie $2,5 \mathrm{~mm}, \mathrm{c}$ ) promień gięcia $135 \mathrm{~mm}$, najdłuższe pęknięcie 2,0 $\mathrm{mm}$

Fig. 3. The weld faces of Inconel 617 alloy sheets with a thickness of $3 \mathrm{~mm}$ with present cracks: a) bending radius $38 \mathrm{~mm}$, the longest crack $3.0 \mathrm{~mm}$, b) bending radius $85 \mathrm{~mm}$, the longest crack $2.5 \mathrm{~mm}, \mathrm{c}$ ) bending radius $135 \mathrm{~mm}$, the longest crack $2.0 \mathrm{~mm}$

zestawiono w tablicy II oraz na rysunku 4, natomiast wyniki przeprowadzonej analizy z obszaru pęknięcia przedstawiono na rysunku 5.

\section{Wyniki i ich dyskusja}

Na podstawie analizy lica wykonanych przetopień (rys. 3) stwierdzono, że wraz ze wzrostem promienia krzywizny bloku matrycowego zmniejsza się długość najdłuższego pęknięcia. Dla płyty o grubości $3 \mathrm{~mm}$ przy promieniu gięcia wynoszącym $38 \mathrm{~mm}$, pęknięcie ma długość $3 \mathrm{~mm}$ (rys. 3a). Dla tej samej płyty przy promieniu bloku $85 \mathrm{~mm}$ długość najdłuższego pęknięcia wynosi $2,5 \mathrm{~mm}$ (rys. $3 \mathrm{~b}$ ), a dla promienia $135 \mathrm{~mm}$ pęknięcie jest równie $2 \mathrm{~mm}$ (rys. 3c).

Wyniki przeprowadzonej próby Transvarestraint zestawiono w tablicy II. Wykazano, że w warunkach wymuszonych odkształceń złącza spawanego ze stopu Inconel 617 wraz ze wzrostem wielkości odkształcenia zwiększa się długość najdłuższego pęknięcia, liczba pęknięć oraz suma długości pęknięć dla płyt próbnych o grubości 3 i $5 \mathrm{~mm}$. Przykładowe zależności dla płyty o grubości $3 \mathrm{~mm}$ przedstawiono graficznie na rysunku 4. Dla badanego materiału na podstawie otrzymanych wyników próby Transvarestraint określono próg kruchości wysokotemperaturowej. Dla blachy o grubości $3 \mathrm{~mm}$ próg wynosi 1\%, natomiast dla blachy

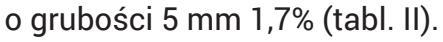

Na podstawie przeprowadzonych badań metalograficznych stwierdzono, że pęknięcia gorące rozwijały się prostopadle do linii wtopienia po granicach kryształów (rys. 5a). $\mathrm{Na}$ podstawie wyników badań przeprowadzonych za pomocą skaningowego mikroskopu elektronowego z przełomu pęknięcia (rys. 5b), stwierdzono, że pęknięcia tworzą się międzykrystalicznie po granicach dendrytów. Pęknięcia gorące powstały w zakresie kruchości wysokotemperaturowej (ZKW), co potwierdzają powierzchnie dendrytów wraz z odkształconymi i zerwanymi mostkami pomiędzy nimi (rys. 5c).

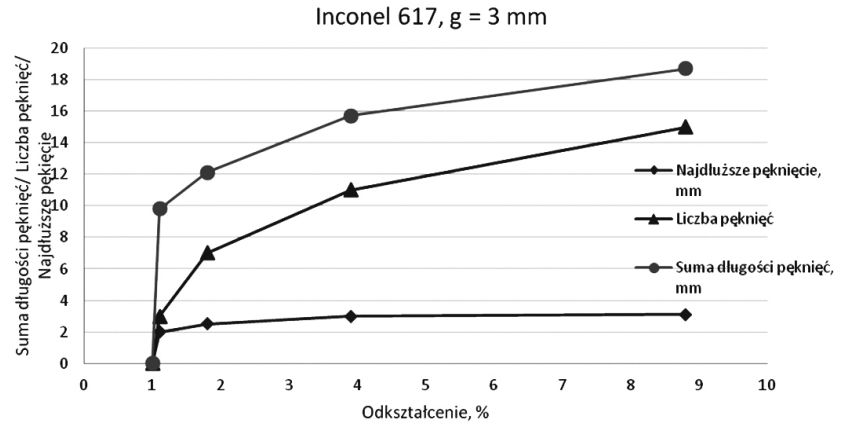

Rys. 4. Zależność odkształcenia od długości najdłuższego pęknięcia, liczby pęknięć i sumy długości pęknięć dla płyt próbnych o grubości $3 \mathrm{~mm}$

Fig. 4. The relationship between the largest crack of length, cracking numbers and the cracking length sum for test sheets with $3 \mathrm{~mm}$ thickness

Tablica II. Wyniki próby Transvarestraint dla stopu Inconel 617 Table II. Results of Transvarestraint test for Inconel 617 alloy

\begin{tabular}{|c|c|c|c|c|c|}
\hline $\begin{array}{c}\text { Promień bloku } \\
\text { matrycowego, mm }\end{array}$ & Grubość blach, mm & Odkształcenie, \% & $\begin{array}{c}\text { Najdłuższe } \\
\text { pęknięcie, mm }\end{array}$ & Liczba pęknięć & $\begin{array}{l}\text { Suma długości } \\
\text { pęknięć, mm }\end{array}$ \\
\hline 150 & 3 & 1,0 & 0,0 & 0,0 & 0,0 \\
\hline 135 & 3 & 1,1 & 2,0 & 3,0 & 9,8 \\
\hline 85 & 3 & 1,8 & 2,5 & 7,0 & 12,1 \\
\hline 38 & 3 & 3,9 & 3,0 & 11,0 & 15,7 \\
\hline 17 & 3 & 8,8 & 3,1 & 15,0 & 18,7 \\
\hline 150 & 5 & 1,7 & 0,0 & 0,0 & 0,0 \\
\hline 135 & 5 & 1,9 & 2,2 & 6,0 & 15,5 \\
\hline 110 & 5 & 2,3 & 2,5 & 9,0 & 18,3 \\
\hline 85 & 5 & 2,9 & 2,9 & 12,0 & 25,1 \\
\hline 55 & 5 & 4,5 & 3,1 & 11,0 & 30,7 \\
\hline 38 & 5 & 6,6 & 3,6 & 15,0 & 34,5 \\
\hline 17 & 5 & 14,7 & 3,9 & 17,0 & 37,1 \\
\hline
\end{tabular}



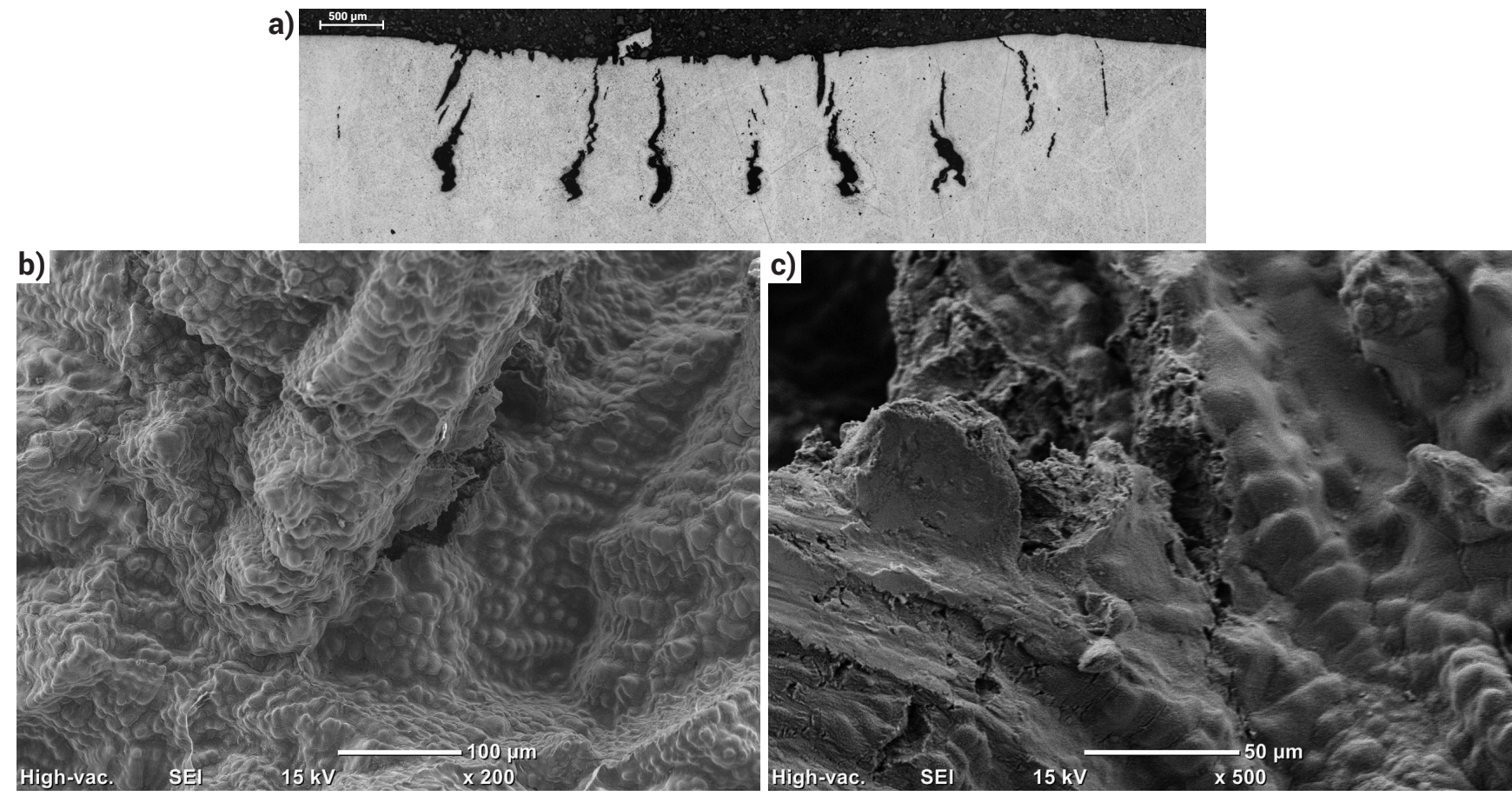

Rys. 5. Struktura przetopienia po próbie Transvarestraint: a) ujawnione pęknięcia na przekroju poprzecznym; b) powierzchnia przełomu, widoczne pęknięcia po graniach krystalitów; c) powierzchnia pęknięcia, zerwane mostki między dendrytami

Fig. 5. The structure of remelting after Transvarestraint test: a) discovered cracks in the cross-section; b) the face of remelting; c) cracking surface

\section{Wnioski}

Na podstawie przeprowadzonych badań i analizy wyników sformułowano następujące wnioski:

1. Dostarczony materiał w postaci blach o grubości 3 i $5 \mathrm{~mm}$ ze stopu Inconel 617 spełnia wymagania specyfikacji normy ASME SB-168:2013 o dopuszczalnej procentowej zawartości pierwiastków.

2. Na podstawie przeprowadzonej próby Transvarestraint $w$ warunkach wymuszonych odkształceń złącza ze stopu Inconel 617 stwierdzono, że wraz ze wzrostem wielkości odkształcenia zwiększa się liczba pęknięć, długość najdłuższego pęknięcia i suma długości pęknięć. Wykazano, że wraz ze wzrostem promienia bloku matrycowego zmniejsza się długość najdłuższego pęknięcia w płycie próbnej. Najdłuższe pęknięcie dla blachy o grubości 3 mm wynosiło 3 mm (promień bloku matrycowego $r=17 \mathrm{~mm}$ ), a dla grubości $5 \mathrm{~mm}$ było równe 3,9 mm (promień bloku matrycowego $\mathrm{r}=17 \mathrm{~mm}$ ). Suma długości pęknięć dla płyty próbnej o grubości $3 \mathrm{~mm}$ dla tego samego promienia bloku wynosi 18,7 mm, a dla blachy o grubości $5 \mathrm{~mm}$ suma długości pęknięć była prawie dwukrotnie większa i wynosiła 37,1 mm. Wyznaczony próg kruchości dla blachy o grubości $3 \mathrm{~mm}$ jest równy 1\%, natomiast dla blachy o grubości $5 \mathrm{~mm}$ 1,7\%.

3. Stwierdzono, że ujawnione pęknięcia w próbie Transvarestraint są pęknięciami gorącymi, które tworzą się prostopadle do linii wtopienia po granicy narastających kryształów kolumnowych (międzykrystalicznie). Pęknięcia gorące powstały w zakresie kruchości wysokotemperaturowej, o czym świadczą odkształcone i zerwane mostki pomiędzy kryształami w spoinie. Zerwanie mostków następuje wskutek braku zdolności dendrytów do przenoszenia odkształceń w trakcie krystalizacji spoiny, tj. w obszarze współistnienia fazy stałej i ciekłej. Potwierdzonym w badaniach efektem końcowym kruchości wysokotemperaturowej są naderwania struktury stopu Inconel 617.

\section{Literatura}

[1] Hernas A., Dobrzański J., Pasternak J., Fudali S.: Charakterystyki nowej generacji materiałów dla energetyki, Wydawnictwo Politechniki Śląskiej, Gliwice, 2015

[2] Adamiec J.: Własności korozyjne napawanych warstw na elementach kotłów do spalania biomasy i odpadów komunalnych, w: Procesy niszczenia oraz powłoki ochronne stosowane w energetyce, s. 201-218, Słok k/ Bechłatowa,12-13 marca 2015.

[3] Stewart C.: Nickel - Based Super Alloys, pp. 1-9, INSG Insight, nr 20, 2013.

[4] Klöwer J., Husemann R. U., Bader M.: Development of Nickel Alloys Based on Alloy 617 for Components in $700^{\circ} \mathrm{C}$ Power Plants, Procedia Engineering, nr 55, pp. 226-331, 2013.

[5] Liu W., Lu F., Yang R., Tang X., Cui H.: Gleeble simulation of the HAZ in Inconel 617 welding, Journal Materials Processing Technology, 225, pp. 221-228, 2015.

[6] Pavan A.H.V., Vikrant K.S.N., Ravibharath R., Singh K.: Development and evaluation of SUS 304H - IN 617 welds for advanced ultra supercritical boiler application, Materials Science \& Engineering, 642, pp. 32-41, 2015.
[7] Tasak E.: Metalurgia spawania, Wydawnictwo JAK, Kraków 2008.

[8] Tasak E., Ziewiec A.: Pękanie spoin w procesie krzepnięcia, Przegląd Spawalnictwa, nr 1, s. 14-18, 2007.

[9] Prokhorov N.N.: Russian Castings Production 2, 1962.

[10] Lancaster J.F.: The metallurgy of welding, brazing and soldering, George Allen\& Unwin Ltd, London 1965.

[11] DuPont J., Lippold J., Kiser S.: Welding metallurgy and weldability of nickel-base alloys, John Wiley \& Sons, New York, 2009.

[12] Norma ASME SB-168:2013: Specification for nickel-chromium-iron alloys (UNS N06600, N06601, N06603, N06690, N06693, N06025, and N06045) and nickel-chromium-cobalt-molybdenum alloy (UNS N06617) plate, sheet and strip.

[13] Adamiec J.: Spawalność odlewniczych stopów magnezu, Wydawnictwo Politechniki Śląskiej, Gliwice 2010. 